\title{
Citra Perempuan Jawa dalam Novel Canting Karya Arswendo Atmowiloto dan Amba Karya Laksmi Pamuntjak
}

\author{
Nur Vitarini Maghfiroh \\ UIN Maulana Malik Ibrahim Malang \\ Jl. Gajayana No.50, Kota Malang, Jawa Timur \\ E-mail: vitarini90@yahoo.com
}

\begin{abstract}
Abstrak: Tujuan penelitian ini adalah mendeskripsikan:(1) citra diri perempuan Jawa dalam novel Canting karya Arswendo Atmowiloto dan Amba karya Laksmi Pamuntjak, (2) peran perempuan Jawa dalam keluarga pada novel Canting karya Arswendo Atmowiloto dan Amba karya Laksmi Pamuntjak, dan (3) peran perempuan Jawa dalam masyarakat pada novel Canting karya Arswendo Atmowiloto dan Amba karya Laksmi Pamuntjak. Penelitian ini adalah penelitian kualitatif dengan kajian sastra bandingan yang mengacu pada metode analisis isi. Data dalam penelitian ini diperoleh dari narasi dan dialog di dalam novel Canting karya Arswendo Atmowiloto dan Amba karya Laksmi Pamuntjak yang berbentuk kutipan-kutipan. Berdasarkan temuan penelitian dan pembahasan, dapat disimpulkan hal-hal berikut. Pertama, Citra diri perempuan Jawa terbagi menjadi dua aspek, yaitu aspek fisik dan psikis. Kedua, terdapat tiga aspek yang dibandingkan dalam kaitannya dengan peran perempuan Jawa dalam keluarga antara novel Canting dan Amba, yaitu aspek pengambilan keputusan dalam keluarga, aspek ekonomi, dan aspek seksualitas. Ketiga, baik novel Canting maupun Amba, masih terdapat stereotip negatif bahwa perempuan masih menjadi makhluk nomor dua ketika berada di sektor publik dan tidak diberi hak mengenyam pendidikan yang sama dengan laki-laki.
\end{abstract}

Kata Kunci: citra, perempuan Jawa, Canting, Amba

Abstract: This research describes: (1) the self image of Javanese women in Canting by Arswendo Atmowiloto and Amba by Laksmi Pamuntjak, (2) the role of Javanese women in domestic in Canting by Arswendo Atmowiloto and Amba by Laksmi Pamuntjak, and (3) the role of Javanese women in public in Canting by Arswendo Atmowiloto and Amba by Laksmi Pamuntjak. This research is qualitative research by using comparative literature studies which refers to content analysis method. 
ISSN 2622-1810 (p) 2622-1829 (e)

Data in this research is get from dialogs and narrative from Canting by Arswendo Atmowilotoand Amba by Laksmi Pamuntjakin quotes. Based on the finding of research and discuss, it can be concluded as follows. Firsty, the self image of Javanese women is divided into two aspects, physical and psychological aspects. Secondly, there are three aspects of Javanese women's role in domestic compared between Canting and Amba, decision-making in the family aspect, economic aspect and sexuality aspect. Thirdly, both of Canting and Amba describes the negative stereotypes that women are being seen as the second human being in the public sector and are not given the same right to education as men.

Kata Kunci: image, Javanese women, Canting, Amba

\section{Pendahuluan}

Karya sastra adalah tiruan (mimesis) dari fenomena-fenomena yang terjadi dalam kehidupan nyata manusia karena karya sastra merupakan cerminan masyarakat. Oleh karena itu, permasalahan yang diangkat dalam karya sastra selalu mencerminkan fenomena yang terjadi dalam kehidupan nyata manusia. Selain itu, karya sastra bersifat menyenangkan dan bermanfaat (dulce etutile). Menyenangkan berarti karya sastra bisa memberi penghiburan terhadap pembacanya karena kata-kata indah di dalamnya. Karya sastra juga memiliki manfaat karena di dalamnya mengandung nilai-nilai kehidupan yang berkaitan dengan permasalahan moral, sosial, budaya, dan agama.

Dalam penciptaannya, karya sastra sebagai cermin kehidupan tidak terlepas dari sebuah sistem yang berlaku di masyarakat. Budaya tertentu yang berlaku dalam masyarakat akan selalu muncul dalam setiap karya sastra baik secara tersurat maupun tersirat. Dengan demikian, kita kembali membahas sifat karya sastra yang bermanfaat. Dengan membaca sebuah karya sastra, kita dapat mengetahui budaya dan kebiasaan suatu kelompok masyarakat.

Dalam sastra Indonesia, permasalahan pokok perempuan telah banyak diangkat dalam karya fiksi. Namun, dalam bidang penelitian sastra, belum banyak penelitian yang memfokuskan pada citra perempuan Jawa dalam kaitannya dengan nilai-nilai kebudayaan Jawa yang dianutnya. Padahal, novel-novel berlatar budaya Jawa telah banyak ditulis oleh pengarang-pengarang handal baik di masa lalu maupun saat ini. Karena seringnya kebudayaan Jawa diangkat dalam sastra Indonesia, 
Hellwig (2003: 5) mengungkapkan bahwa sastra Indonesia modern adalah java-centered (berpusat pada Jawa) mengingat bahwa sebagian besar pengarang adalah orang Jawa atau berasal dari kelompok etnis lain namun tinggal di Jawa.

Penelitian ini membandingkan novel Canting karya Arswendo Atmowiloto dan Amba karya Laksmi Pamuntjak. Hal ini karena persentuhan merupakan hal yang mungkin terjadi antarkarya sastra. Hampir tidak mungkin ada karya sastra tanpa adanya persentuhan dengan karya sastra lain dan otonom. Saling memengaruhi dan berhubungan merupakan hal yang mungkin terjadi dalam karya sastra. Oleh karena itu, diperlukan adanya kajian sastra bandingan untuk menemukanpersamaan, perbedaan, serta keterkaitan novel Canting karya Arswendo Atmowiloto dan Amba karya Laksmi Pamuntjak.

Adapun yang dibandingkan dalam penelitian ini adalah citra perempuan Jawa. Sugihastuti (2000: 43) mengungkapkan bahwa citra merupakan rupa dan gambaran (dapat berupa gambaran yang dimiliki orang banyak mengenai pribadi, atau kesan mental atau bayangan visual yang ditimbulkan oleh sebuah kata, frasa atau kalimat dan merupakan unsur dasar yang khas dalam karya prosa dan puisi. Ia membagi citra perempuan ke dalam dua bagian besar, yaitu citra diri dan citra sosial (Sugihastuti: 2000, 68). Citra diri terbagi menjadi dua aspek, yaitu aspek fisik dan aspek psikis. Begitu juga dengancitra sosial yang terbagi menjadi dua aspek, yaitu peran dalam keluarga dan peran dalam masyarakat.

Dalam penelitian ini, kata perempuan lebih dipilih daripada wanita. Hal ini berdasarkan pertimbangan bahwa secara etimologis, wanita dalam bahasa Jawa berarti wani ditata (berani diatur), sedangkan perempuan bermakna lebih positif karena berasal dari kata dasar empu dengan imbuhan per-an (Budiman: 1992, 72). Berdasarkan pertimbangan tersebut, kata perempuan lebih dipilih daripada wanita.

Penulis menggunakan kajian sastra bandingan dalam mengkaji dua novel tersebut. Menurut Wellek \& Warren (1970: 47), sastra bandingan adalah studi sastra dengan tujuan untuk mengetahui dan menganalisis hubungan dan pengaruhnya antara karya satu terhadap karya lain serta ciri-ciri yang dimilikinya. Konsep tersebut ditambahkan oleh Endraswara (2011: 130) bahwa studi sastra bandingan merupakan upaya inter- 
ISSN 2622-1810 (p) 2622-1829 (e)

disipliner, yakni lebih banyak memperhatikan hubungan sastra menurut aspek waktu dan tempat. Dari aspek waktu, sastra bandingan dapat membandingkan dua atau lebih periode yang berbeda. Adapun konteks tempat akan mengikat sastra bandingan menurut wilayah geografis sastra, bahkan kajian ini juga dapat membandingkan sastra dengan bidang lain.

Penelitian ini bertujuan untuk mendeskripsikan secara jelas mengenai citra diri, peran perempuan Jawa dalam keluarga, dan peran perempuan Jawa dalam masyarakat pada novel Canting karya Arswendo Atmowiloto dan Amba karya Laksmi Pamuntjak. Penelitian ini diharapkan dapat memberi kontribusi dalam ragam penelitian sastra Indonesia, khususnya kajian sastra bandingan.

\section{Metodologi Penelitian}

Penelitian ini merupakan penelitian kualitatif dengan kajian sastra bandingan. Penelitian ini bertujuan untuk mendeskripsikan (1) citra diri perempuan Jawa dalam novel Canting karya Arswendo Atmowiloto dan Amba karya Laksmi Pamuntjak, (2) peran perempuan Jawa dalam keluarga pada novel Canting karya Arswendo Atmowiloto dan Amba karya Laksmi Pamuntjak, dan (3) peran perempuan Jawa dalam masyarakat pada novel Canting karya Arswendo Atmowiloto dan Amba karya Laksmi Pamuntjak.

Data dalam penelitian ini berupa data verbal yang didapat dari narasi dan dialog di dalam novel Canting karya Arswendo Atmowiloto dan Amba karya Laksmi Pamuntjak yang berbentuk kutipan-kutipan. Data-data yang diambil dikhususkan hanya pada data yang berhubungan dengan citra diri, peran dalam keluarga dan peran dalam masyarakat.

Prosedur pengumpulan data dalam penelitian ini merujuk pada model Miles dan Huberman (Siswantoro, 2005: 67). Pertama, mengumpulkan data dengan mengambil data berkali-kali untuk keakuratan dan kualitas data. Pengumpulan data ini dilakukan dengan beberapa teknik, yaitu studi terhadap novel Canting dan novel Amba, mengidentifikasi data-data yang telah diperoleh dari kedua novel, menginterpretasi data, dan analisis data. Kedua, setelah data terkumpul, 
dilakukan penyeleksian data agar data yang telah ditemukan dari kedua novel yang didapat menjadi terfokus dan akurat. Penyeleksian tidak hanya dilakukan dengan menghilangkan data-data yang dianggap tidak perlu, tetapi juga mengklasifikasikan data sesuai dengan subfokus penelitian dan konsep kajian sastra bandingan. Ketiga, menarik simpulan dengan merujuk pada kegiatan analisis dalam usaha memperoleh kepastian tentang kebenaran data. Kegiatan ini dilakukan bersamaan dengan pengumpulan dan penyeleksian data. Untuk memeroleh kepastian mengenai keakuratan data, tindakan mengecek perlu dilakukan. Dengan mengecek kembali perolehan data, akan menjadikan data yang berkualitas dan tidak bias. Keempat, pengabsahan data untuk mendapatkan data yang valid, data perlu diuji kembali. Teknik yang digunakan dalam proses validasi dalam penelitian sastra ini adalah triangulasi yang meliputi triangulasi data, triangulasi teori dan triangulasi peneliti.

\section{Hasil Temuan dan Pembahasan}

Berdasarkan temuan penelitian serta pembahasan penelitian, terdapat temuan mengenai citra diri perempuan Jawa, peran perempuan Jawa dalam keluarga, dan peran perempuan Jawa dalam masyarakat. Berikut pembahasan dari ketiga hal tersebut.

1. Citra Diri Perempuan Jawa dalam Novel Canting Karya Arswendo Atmowiloto dan Amba Karya Laksmi Pamuntjak

Terdapat dua aspek yang ditemukan berkaitan dengan citra diri perempuan Jawa, yaitu aspek fisik dan aspek psikis. Aspek fisik berkaitan dengan gambaran keadaan fisik tokoh, sedangkan aspek psikis berkaitan dengan gambaran keadaan di luar fisik tokoh.

Aspek Fisik

Pada novel Canting, fisik tokoh perempuan Jawa tidak banyak ditampilkan. Namun, tokoh Ni sedikit ditampilkan sebagai gadis yang berkulit hitam seperti dalam kutipan berikut.

"Anakmu sudah lahir, Bu," kata Pak Bei di samping Bu Bei yang masih susah mengatur napas. 
ISSN 2622-1810 (p) 2622-1829 (e)

"Hitam seperti jangkrik."

Bu Bei menangis... $(C: 78)$

Hal ini mengandung anggapan bahwa Ni bukanlah anak kandung Pak Bei karena Pak Bei adalah priyayi berkulit putih dan berhidung mancung. Namun, Ni sendiri tidak terlalu mempermasalahkan keadaan fisiknya itu. Novel Canting menitikberatkan pada pesan-pesan moral yang tidak berkaitan dengan aspek fisik tokoh tetapi berkaitan dengan aspek psikisnya. Misalnya, berkaitan dengan kekuatan mental dan ketangguhan para tokoh perempuannya.

Adapun pada novel $A m b a$, aspek fisik para tokoh perempuannya lebih banyak ditampilkan daripada pada novel Canting. Masing-masing tokoh perempuan digambarkan secara jelas keadaan fisiknya. Nuniek dan kedua anak kembarnya, Ambika dan Ambalika, ditampilkan sebagai perempuan-perempuan yang cantik dan digandrungi oleh banyak lakilaki. Adapun Amba ditampilkan berbeda dengan kedua adik kembar dan ibunya. Ia tidak terlalu cantik secara fisik tetapi memiliki daya pikat tersendiri yang berhubungan dengan citra psikisnya.

Adapun dalam novel Amba, digambarkan bahwa perempuan Jawa itu haruslah cantik, anggun, dan cakap seperti halnya tampilan fisik Nuniek, Ambika dan Ambalika. Namun, yang banyak ditampilkan sebagai perempuan yang cantik dan pemikirannya adalah Nuniek dan Ambika, sedangkan Ambalika tidak banyak diceritakan selain kecantikan fisiknya saja. Mereka di samping memiliki kecantikan fisik, juga memiliki kemampuan lain seperti menari dan menjadi sinden. Konsep kecantikan seperti itu telah disetujui oleh Ambika dan masyarakat sehingga anak perempuan yang memiliki penampilan kurang cantik seperti Amba merasa kurang percaya diri dan berusaha melakukan segala cara agar terlihat cantik sesuai konsep kecantikan yang ada sebagaimana dalam kutipan berikut.

"Maka ia berusaha menghabiskan makanan di piringnya tanpa dipaksa, menahan diri tak menangis ketika diizinkan sesuatu, belajar memasak, membaca, menulis dengan rapih...bukankah ini nasib kebanyakan perempuan, untuk menjadi yang tercantik?" (A: 85) 
Aspek Psikis

Menurut Handayani \& Novianto (2008: 119), perempuan Jawa memiliki karakter yang khas sesuai dengan kultur Jawa pada umumnya, yaitu bertutur kata halus, tenang, diam/kalem, tidak suka konflik, mementingkan harmoni, menjunjung tinggi nilai keluarga, mampu mengerti dan memahami orang lain, sopan, pengendalian diri tinggi/terkontrol, daya tahan untuk menderita tinggi, memegang peranan secara ekonomi, dan setia/loyalitas tinggi.

Pada novel Canting, karakter daya tahan untuk menderita yang tinggi dan pengendalian diri terkontrol dapat dilihat sebagaimana pada sikap batin $\mathrm{Bu}$ Bei dalam novel Canting yang mengabdikan seluruh hidupnya sebagai istri Pak Bei. Kalimat Bu Bei menunggu yang tertulis berkali-kali menunjukkan sikap batinnya yang diliputi oleh kepasrahan dan ketundukannya pada Pak Bei. Sikap menunggunya itu juga menunjukkan kepasifan $\mathrm{Bu}$ Bei dalam pengambilan keputusan di bawah Pak Bei. Ia menunggu dan Pak Bei memutuskan, seperti dalam kutipan berikut.

"Bu Bei menunggu.

Kalau tiba-tiba Pak Bei meneriakkan keputusan penting bagi hidup $\mathrm{Bu}$ Bei. Misalnya mengingatkan akan kandungan atau menceraikan. Atau menghentikan kegiatan.

Bu Bei menunggu.

Kalau tiba-tiba Pak Bei meneriakkan keputusan penting bagi hidup $\mathrm{Bu}$ Bei. Misalnya mengingatkan akan kandungan atau menceraikan. Atau menghentikan kegiatan.

Bu Bei menunggu." (C: 48)

Berbeda dengan sikap Bu Bei yang selalu menunggu, kalimat Ni tahu bahwa ia ditunggu(C: 149) yang menjadi awal dari bab tiga novel Canting menekankan perbedaan sikap $\mathrm{Ni}$ dan $\mathrm{Bu}$ Bei. Terdapat perbedaan yang signifikan antara dua generasi tersebut. Ni juga berusaha menghapus jarak antara priyayi dan wongcilik yang selama ini diterapkan dalam keluarganya.Kutipan ini adalah salah satu sikap yang ditunjukkan oleh $\mathrm{Ni}$ terhadap buruh di rumahnya. 
ISSN 2622-1810 (p) 2622-1829 (e)

"Ni mengambil tempat duduk di samping Mbok Tuwuh. Sehingga membuat Mbok Tuwuh agak kikuk. Menggeser sedikit tempat duduknya di atas tikar." (C: 196)

Adapun pada novel $A m b a$, citra perempuan Jawa yang penuh bakti dan tulus juga ditampilkan pada tokoh Nuniek. Meski memiliki pemikiran sendiri, ia tahu kapan harus berbicara dan kapan harus diam. Walaupun mengetahui banyak hal, ia tidak bisa menunjukkan sepenuhnya pada suaminya karena ia tahu bahwa kelebihannya menuntut pengorbanan untuk selalu tampil rendah hati dan ingin tetap menjaga wibawa suaminya. Berikut adalah kutipan yang menunjukkan sikap Nuniek yang tulus dan rendah hati.

"Ibu punya pikirannya sendiri. Amba tahu itu. Diam-diam, ia tahu bahwa Ibu, mungkin sejak ia bertahun-tahun yang lampau memutuskan untuk tidak melarikan diri bersama Srimulat dan Orkes Bunga Mawar, tidak bisa menunjukkan pada suaminya bahwa ia mengerti lebih banyak dari apa yang ia akui." (A: 109)

Amba sebagai tokoh generasi muda menampakkan sikap tidak ingin menjadi pihak yang menunggu. Ketika tunangannya, Salwa, ditugaskan oleh tempat kerjanya untuk mengajar di Surabaya, Amba tidak ingin dianggap lemah dan menjadi pihak yang menunggu sehingga ia pergi ke Kediri untuk memenuhi lowongan pekerjaan sebagai penerjemah dokumen medis. Berikut adalah kutipannya.

"Aku butuh berada di sini. Di tengah kekerasan sekalipun. Aku butuh karena aku tak sudi menunggu. Bahkan untuk sebuah kabar baik. Aku ingin menghadirkan diri untuk nasib, apabila memang benar aku terbelenggu oleh takdir; aku tak hendak menghindarinya seperti orang-orang yang manja." (A: 185)

2. Peran Tokoh Perempuan Jawa dalam Keluarga pada Novel Canting Karya Arswendo Atmowiloto dan Amba Karya Laksmi Pamuntjak

Geertz (1983: 48) mengungkapkan bahwa dimensi pertanggungjawaban untuk keputusan penting mengenai pengurusan rumah tangga berkisar dari dominasi oleh istri sampai suami-istri hampir sederajat 
sepenuhnya ada di bawah bayang-bayang suaminya, tetapi sebaliknya terdapat suami yang menyerah tanpa daya pada istri.

Hal itu bertolak belakang dengan pola kerja sama dalam aspek pengambilan keputusan yang terjadi pada keluarga $\mathrm{Bu}$ Bei dalam novel Canting. Segala permasalahan di dalam rumah Pak Bei yang memutuskan. Pak Bei begitu mendominasi dalam pengambilan keputusan dalam keluarga, sedangkan $\mathrm{Bu}$ Bei hanya bersikap pasif dan menunggu keputusan Pak Bei. Hampir tidak ada dialog yang dilakukan oleh Bu Bei dengan suaminya. Berikut adalah kutipan yang menunjukkan dominasi Pak Bei terhadap segala keputusan.

"Bu Bei menunggu.

Kalau tiba-tiba Pak Bei meneriakkan keputusan penting bagi hidup $\mathrm{Bu}$ Bei. Misalnya mengingatkan akan kandungan atau menceraikan. Atau menghentikan kegiatan.

Bu Bei menunggu.

Kalau tiba-tiba Pak Bei meneriakkan keputusan penting bagi hidup $\mathrm{Bu}$ Bei. Misalnya mengingatkan akan kandungan atau menceraikan. Atau menghentikan kegiatan.

Bu Bei menunggu." (C: 48)

Pada aspek ekonomi, pola kerja sama ekonomi yang terjadi dalam novel Canting adalah istri sebagai tulang punggung keluarga. Perusahaan batik Cap Canting sepenuhnya dijalankan oleh Bu Bei. Adapun kegiatan Pak Bei sehari-hari hanya mengamat-amati binatang-binatang peliharaan kesayangannya yang itu pun telah ada sendiri buruh yang mengerjakannya. Pak Bei juga aktif dalam kegiatan-kegiatan sosial dan politik tetapi kegiatan tersebut tidak berpengaruh terhadap perekonomian keluarga.

Pada aspek yang berkaitan dengan hak-hak seksualitas suami-istri, meskipun ia sedang marah, sikap melayani ditunjukkan sebagai kewajiban seorang istri. Ia tampak bahagia bahwa Pak Bei masih menjamahnya setelah sekian lama, kepuasannya sendiri tidaklah menjadi hal yang penting. 
ISSN 2622-1810 (p) 2622-1829 (e)

Adapun pada novel $A m b a$, pada aspek pengambilan keputusan terdapat keseimbangan dalam pengambilan keputusan setiap permasalahan rumah tangga pada keluarga Nuniek dan Sudarminto. Bahkan Sudarminto cenderung mengalah dengan pendapat istrinya seperti dalam kutipan berikut.

"Namun, akhirnya Sudarminto kalah. Amba yang menguping dari kamarnya juga tahu inilah yang akan terjadi. Bapak tak senang melarut-larutkan masalah, sementara, Ibu tahu kapan mengalah utuk menang. Malamnya, ketika Ibu meracau lagi: Suka atau ndak suka, apa salahnya mempertemukan mereka? Apa salahnya apabila mereka kenalan?

Pertahanan Bapak runtuh.

"Kamu benar, Bu. Memang tidak ada salahnya kalau mereka ketemu," ujar Bapak dengan nada separuh murung. (A: 141)"

Pada aspek ekonomi, pola kerja sama dalam novel Ambasedikit berbeda dengan yang ada dalam novel Canting, yaitu suami melakukan pekerjaan produktif di luar dan istri mengerjakan beberapa pekerjaan ringan di rumah dengan membuat kue-kue tradisional untuk dititipkan di warung orang lain. Nuniek tidak pernah dipaksa Sudarminto untuk ikut mencari nafkah karena memang penghasilan Sudarminto sebagai guru dan kepala sekolah telah mencukupi kebutuhan sehari-hari keluarganya, tetapi dengan berdagang kue itu ia merasa menjadi istri yang berharga karena ikut menambah penghasilan keluarganya meskipun hasilnya tidak seberapa.

Pada aspek hak-hak seksualitas suami-istri, dalam novel Ambatidak banyak ditemukan problematikanya. Masing-masing baik Sudarminto sebagai suami maupun Nuniek sebagai istri menunjukkan kesetiaan dan kedekatan emosional yang tidak banyak ditampakkan dalam hubungan perkawinan Pak Bei dan Bu Bei dalam novel Canting. Nuniek juga menyadari kewajibannya dalam melayani suami.

3. Peran Tokoh Perempuan Jawa dalam Masyarakat pada Novel Canting Karya Arswendo Atmowiloto dan Amba Karya Laksmi Pamuntjak 
Di samping perannya dalam keluarga, terdapat beberapa peran perempuan Jawa yang muncul dalam novel Canting dan Amba. Peran perempuan Jawa dalam masyarakat berkaitan dengan hubungan para tokoh perempuan Jawa dengan masyarakat dan lingkungannya serta sikap sosialnya. Sikap sosial adalah konsistensi individu dalam memberikan respon terhadap objek-objek sosial, termasuk terhadap pria sebagai pasangan jenis kelaminnya (Sugihastuti, 2000: 131).

Pada novel Canting, seluruh gerakan perekonomian di keluarga $\mathrm{Bu}$ Bei yang memegangnya. Ia mengawasi seluruh pembuatan batik di kediaman Ngabehi hingga membawanya ke Pasar Klewer untuk dijual. Oleh karena itu, novel Canting menampilkan satu tempat yang menyediakan ruang khusus bagi kekuasaan perempuan, yaitu pasar. Pendapat Geertz (1983: 127) yang mengungkapkan bahwa pasar di Jawa dikuasai oleh perempuan pun benar adanya. Di sanalah perempuan menemukan kebebasan yang mungkin tidak ditemukan di dalam rumah, tidak terkecuali dengan $\mathrm{Bu}$ Bei. Ketika di rumah $\mathrm{Bu}$ Bei tidak diberi kesempatan untuk ikut mengambil keputusan, di pasar ia yang memutuskan dan memilih. Jika Bu Bei merasa becak yang mengantarnya dari rumah ke pasar terlalu cepat, maka ia tidak akan memilihnya lagi lain kali. Jika ada permasalahan yang berkaitan dengan transaksi jual beli di kiosnya, maka ia juga lah yang memutuskan masalah-masalah yang sulit itu. Begitu besarnya peran perempuan Jawa di pasar, hingga dikatakan dalam Canting bahwa pasar adalah pameran kekuasaan perempuan.

Kekuatan publik perempuan Jawa juga ditampilkan pada tokoh Ni. Ketika perusahaan batik milik keluarga Sestrokusumo sudah tidak berjaya lagi, para buruh batik banyak yang sudah tidak melakukan aktivitas membatiknya seperti sedia kala. Mereka kehilangan pekerjaan. Hal itu juga yang mendorong $\mathrm{Ni}$ untuk mengembangkan kembali bisnis batik milik keluarganya. Meskipun awalnya Ni dipandang tidak mampu, pada akhirnya ia berhasil juga mengembangkan kembali bisnis batik milik keluarganya. Dengan keberhasilannya itu, banyak buruh batik yang mendatanginya dan kembali menggantungkan hidup pada usaha miliknya. Hal ini menunjukkan bahwa $\mathrm{Ni}$ adalah salah satu tokoh 
ISSN 2622-1810 (p) 2622-1829 (e)

perempuan Jawa yang memiliki posisi penting dalam kehidupan masyarakat sekitarnya.

Di sisi lain, masih terdapat stereotip dalam masyarakat Jawa bahwa perempuan tidak boleh terlalu menonjolkan dirinya di masyarakat. Stereotip adalah pelabelan atau penandaan negatif terhadap kelompok atau jenis kelamin tertentu (Nugroho, 2008: 10). Stereotip dalam novel Canting tercermin dalam upacara brokohan yang dilakukan oleh keluarga $\mathrm{Bu}$ Bei untuk mensyukuri kelahiran Ni. Dalam adat Jawa, upacara slametan brokohan adalah tradisi yang diadakan sebagai bentuk syukur atas lahirnya seorang bayi yang terdiri dari nasi tumpeng dikelilingi sayuran urap berbumbu pedas (tanda si bayi laki-laki) dan ikan asin goreng tepung, jajanan pasar berupa ubi rebus, singkong, jagung, kacang dan lain-lain, bubur merah-putih, serta sayur lodeh kluwih/timbul agar linuwih (kalau sudah besar sang anak menjadi orang terpandang dan sejahtera). Namun, Bu Bei tidak sengaja membuatkan sayur lodeh kluwihuntuk anak perempuannya saat itu karena ia mendapatkannya dari kiriman desa. Hal itu belum pernah terjadi pada anak perempuan sebelumnya sehingga menunjukkan bahwa anak perempuan yang diharapkan akan kelak menjadi anak menonjol dan terpandang adalah hal yang saru (tabu). Berikut adalah kutipannya:

"Bu Bei di dalam juga bercerita. Secara aneh sekali, waktu brokoban dulu, orang-orang di belakang memasak lodeh kluwih. Itu tak pernah terjadi pada anak perempuan. Hanya anak laki-laki yang biasanya dibuatkan kluwih, buah timbul, karena buah itu mempunyai makna agar si bayi bisa linuwih, bisa menonjol kelak di kemudian hari. Buah kluwih itu memang tidak sengaja merupakan kiriman dari desa." ( $C$ : 106)

Adapun pada novel $A m b a$, adanya stereotip bahwa perempuan adalah makhluk yang dimarginalkan juga dialami oleh tokoh Amba ketika berada di tengah lingkungan sosial Bhisma yang sebagian besar terlibat dalam permasalahan politik. Di sana, Amba seakan menjadi seseorang yang berada di lingkungan asing karena ia jarang diperkenalkan secara resmi pada teman-teman Bhisma dan tidak dilibatkan dalam percakapanpercakapan politik antara mereka. Hal itu dianggap sudah biasa terjadi di 
lingkungan Jawa bahwa perempuan sering kali tidak diperkenalkan dalam acara-acara sosial.

Stereotip negatif mengenai perempuan juga dialami oleh Amba ketika ia ingin meneruskan studinya ke universitas. Hal ini dapat dijumpai dalam novel tersebut, sebagaimana terdapat dalam kutipan berikut:

"Mereka menunggu setahun lamanya, setelah Amba menyelesaikan ujian akhir SMA-nya. Itu berarti ia baru saja ulang tahun ke delapan belas. Delapan belas dan belum menikah. Di Kadipura itu berarti perawan yang tidak laku. Bagi Nuniek tak ada nasib yang lebih mengerikan..." (A: 126)

Dalam kutipan di atas jelas tergambar bahwa Amba harus berhadapan dengan masyarakat, bahkan ibunya sendiri ketika memperjuangkan keinginannya untuk berpendidikan tinggi.

\section{Simpulan dan Rekomendasi}

Dari pembahasan di atas, diperoleh simpulan sebagai berikut. Pertama, Citra diri perempuan Jawa terbagi menjadi dua aspek, yaitu aspek fisik dan psikis. Pada aspek fisik, novel Canting dan Amba memiliki perbedaan yang signifikan dalam menampilkan tokoh-tokoh perempuan Jawa. Novel Canting tidak banyak menampilkan keadaan fisik tokohtokoh perempuannya, sedangkan novel Amba banyak menampilkan keadaan fisik tokoh-tokoh perempuannya yang cantik dan menarik. Dari kedua novel tersebut dapat disimpulkan bahwa perempuan Jawa haruslah cantik secara fisik. Jika tidak cantik secara fisik, perempuan haruslah cakap dan memiliki keterampilan lain yang membuatnya menarik. Pada aspek psikis, kedua novel menampilkan perempuan Jawa yang tulus dan penuh bakti. Pada tokoh-tokoh perempuan Jawa yang lebih muda, kedua novel menampilkan mereka sebagai perempuan yang memiliki keinginan sendiri dan teguh pendiriannya.

Kedua, terdapat tiga aspek yang dapat dibandingkan berkaitan dengan peran perempuan Jawa dalam keluarga antara novel Canting dan $A m b a$, yaitu aspek pengambilan keputusan dalam keluarga, aspek ekonomi, dan aspek seksualitas. Pada aspek pengambilan keputusan dalam keluarga, novel Amba menampilkan pentingnya peran istri dalam 
ISSN 2622-1810 (p) 2622-1829 (e)

pengambilan keputusan setiap masalah di keluarga, sedangkan novel Canting menampilkan dominasi kekuasaan suami di atas istri dalam pengambilan setiap keputusan. Pada aspek ekonomi, novel Canting lebih banyak menampilkan kekuatan istri dari sisi perekonomian yang lebih banyak terlibat dalam kegiatan-kegiatan ekonomi keluarga daripada suami. Sebaliknya, novel Amba menampilkan kekuatan suami sebagai tonggak utama perekonomian keluarga. Pada aspek seksualitas, keduanya menampilkan hak-hak yang belum didapatkan oleh istri, tetapi hal itu dianggap sebagai pelayanan dan pengabdian terhadap suami.

Ketiga, baik Canting maupun Ambaterdapat masih adanya stereotip negatif bahwa perempuan masih dikesampingkan ketika berada di sektor publik dan tidak diberikan hak mengenyam pendidikan yang sama dengan laki-laki. Namun, pada aspek ekonomi, peran positif perempuan Jawa yang telah diakui kemampuannya dalam menggerakkan ekonomi masyarakat ditampilkan dalam novel Canting.

Implikasi penelitian ini banyak terdapat dalam Kurikulum Tingkat Satuan Pendidikan (KTSP) pembelajaran bahasa Indonesia di setiap jenjang pendidikan dengan tingkat kesulitan masing-masing. Salah satunya adalah kelas XII SMA Jurusan Bahasa dengan kompetensi dasar 3.1 menganalisis cerpen yang dianggap penting pada setiap periode untuk menemukan standar budaya yang dianut masyarakat dalam periode tersebut dan 7.1 menjelaskan tema, plot, tokoh, dan perwatakan ragam sastra Indonesia prosa naratif Indonesia dan terjemahan dalam diskusi kelompok. Hal itu dikarenakan gambaran citra perempuan Jawa adalah salah satu konsekuensi dari standar budaya yang dianut oleh masyarakat dan untuk mendapatkan isi dari suatu karya sastra naratif itu, diperlukan terlebih dahulu identifikasi unsur-unsur intrinsiknya berupa tema, plot, serta tokoh dan perwatakan.

Secara praktis, penelitian ini dapat memberikan gambaran tentang bentuk-bentuk kekuatan lain yang dimiliki oleh perempuan Jawa yang selama ini dianggap sebagai the second sexdan tidak diberikan kesempatan lebih dalam mengaktualisasikan dirinya. Bentuk kekuatan lain itu datangnya dari kelemahlembutan dan kekuatan mental perempuan Jawa sehingga dari kelemahlembutan dan kekuatan 
mentalnya itu mereka mendominasi kehidupan keluarga bahkan dapat memengaruhi aspek kehidupan masyarakat.

\section{Daftar Rujukan}

Budiman, Kris, “Citra Wanita dan Kekuasaan (Jawa)", diedit oleh. Budi Susanto, et al. Yogyakarta: Penerbit Kanisius, 1992.

Endraswara, Suwardi. Metodologi Penelitian Sastra: Epistemologi, Model, Teori, dan Aplikasi. Yogyakarta: Caps, 2011.

Geertz, Hildred. Keluarga Jawa. Jakarta: Grafiti Pers, 1983.

Handayani, Christina S. dan Ardhian Novianto. Kuasa Wanita Jawa. Yogyakarta: LkiS, 2008.

Hellwig, Tineke. In The Shadow of Change: Citra Perempuan dalam Sastra Indonesia. Depok: Desantara, 2003.

Nugroho, Riant. Gender dan Strategi Pengaruh-Utamaannya di Indonesia. Yogyakarta: Pustaka Pelajar, 2008.

Siswantoro. Metode Penelitian Sastra: Analisis Psikologis. Surakarta: Muhammadiyah University Press, 2005.

Sugihastuti. Wanita di Mata Wanita: Perspektif Sajak-sajak Toeti Heraty. Bandung: Penerbit Nuansa, 2000.

Wellek, Rene \& Austin Warren. Theory of Literature. London: Cox \& Wyman Ltd, 1970. 
84 | ESTETIK, Vol. 1 No. 1, Juni 2018

ISSN 2622-1810 (p) 2622-1829 (e) 